\title{
Mixed epithelial and stromal tumor of the kidney (MEST) simulating an upper tract TCC
}

\author{
Petros Sountoulides, MD, PhD, FEBU; ${ }^{*}$ Michail Koptsis, MD; ${ }^{*}$ Linda Metaxa, MD; ${ }^{\dagger}$ Alexandros Theodosiou, \\ MD; Dimitrios Kikidakis, MD; ${ }^{*}$ Chrysa Filintatzi, MD; Konstantinos Paschalidis, MD*
}

*Department of Urology, General Hospital of Veria, Greece; 'Radiology Department, General Hospital of Veria, Greece; „Pathology Department, General Hospital of Veria, Greece

Cite as: Can Urol Assoc J 2012;6(1):e23-26. htrp://dx.doi.org/10.5489/cuaj.11042

\section{Abstract}

We present a rare and interesting case of a mixed epithelial and stromal tumour (MEST) of the kidney. The case is unique as it involves a male patient with no history of hormonal therapy presenting with a filling defect in the renal collecting system and positive urine cytology. The patient was diagnosed with transitional cell carcinoma of the renal pelvis and subjected to nephroureterectomy, which revealed a solid tumour arising from the lower calyces and extending into the renal pelvis and upper ureter. Pathology revealed a MEST. The patient was disease-free at the 6-month follow-up.

\section{Case presentation}

A 50-year-old male was found with a mass in his left kidney on abdominal ultrasound during routine evaluation for lower urinary tract symptoms. On colour ultrasound, the mass was irregular, hypoechoic and involved the renal pelvis and lower calyces (Fig. 1). The patient's medical and family histories were insignificant and his physical examination did not reveal any abnormalities. The ultrasound findings were further evaluated with intravenous urography (IVU), which also revealed a smaller (about $9 \mathrm{~cm}$ ) ectopic right kidney located in the true pelvis. The collecting system of the left kidney was mildly dilated with the presence of a filling defect in the lower calyces extending into the renal pelvis. The ectopic, smaller, right kidney was not dilated and the contrast medium was normally secreted to the bladder (Fig. 2).

This finding raised a strong suspicion for transitional cell carcinoma (TCC) of the collecting system, although the patient was not a smoker. We ordered a computed tomography urography (CTU) for further clarification and staging and we planned a cystoscopy.

Cystoscopy revealed a normal bladder urothelium. A ureteral catheter was advanced into the upper tract for bar- botage and urine collection for cytology. Two voided specimens of urine were also collected for cytology. Cytology from the urine collected via the ureteral catheter was positive for high-grade transitional cell carcinoma (TCC).

CTU confirmed the findings of IVU and revealed the presence of a filling defect caused by soft tissue mass arising from the anterior lower calyx and extending into the renal pelvis and the upper part of the ureter. The mass was causing dilatation of the renal pelvis. although there were no signs of enlarged lymph nodes or other pathology (Fig. 3, Fig. 4). Differential diagnosis included hemangioma, tuberculosis and TCC of the collecting system. However, in view of the positive urine cytology, the diagnosis of TCC of the collecting system was considered the most possible diagnosis. Nephroureterectomy was scheduled and nephrology consultation was requested because the patient had a possibly miss-functioning ectopic right kidney and was about to lose his other kidney.

A renal scan with ${ }^{99 \mathrm{~m} T c}$ (DTPA) was done to evaluate renal function. Total glomerular filtration rate was $48 \mathrm{~mL} /$ min (normal: $>74 \mathrm{~mL} / \mathrm{min}$ ) and split renal function was $36.8 \mathrm{~mL} / \mathrm{min}$ for the left kidney $(77 \%$ of the total renal function) and $11 \mathrm{~mL} / \mathrm{min}$ for the ectopic right kidney $(23 \%$ of the total renal function).

The possibility of a temporary or permanent need for renal dialysis postoperatively was explained to the patient. The patient gave informed consent for nephroureterectomy.

Open nephroureterectomy was performed and the patient had a quick and uneventful recovery. Postoperative diuresis was normal and creatinine levels were slightly elevated from preoperative values $(0.75 \mathrm{ng} / \mathrm{dL})$, but did not exceed $1.2 \mathrm{ng} / \mathrm{dL}$. There was no need for supportive renal dialysis and the patient was discharged with a scheduled follow-up visit with the nephrologist.

Pathology examination of the surgical specimen revealed the presence of a smooth, polypoid-like mass measuring $9 \times 2.5 \times 1.5 \mathrm{~cm}$, deriving from a lower pole calyx and partly filling the renal pelvis and upper part of the ureter. The mass 


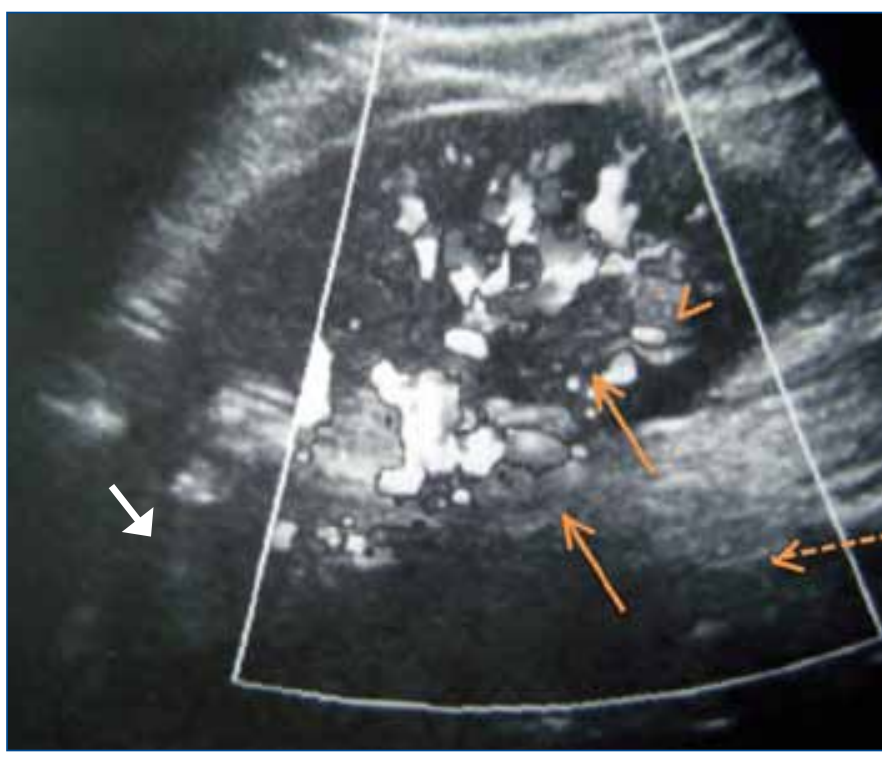

Fig. 1. Ultrasound of the left kidney. Hypoechoic irregular mass is noted in the region of the renal pelvis and the lower calyces. The mass seems to have very poor vascularity.

was a mixed epithelial and stromal tumour (MEST) of the kidney, also known as adult mesoblastic nephroma (Fig. 5, Fig. 6). In immunohistology, epithelial cells were positive for $\mathrm{CK} 7$, while stromal elements were positive for desmin, smooth muscle actin and CD117.

Although the natural history of MESTs is usually benign, the patient was originally placed on a strict follow-up schedule due to the positive urine cytology which could not be accounted for. At the scheduled 3- and 6-month follow-up visits, the patient was doing well, his urine cytology was normal and his follow-up CTs were negative for recurrence or any other signs of malignancy.

\section{Discussion}

The term "mixed epithelial and stromal tumor of the kidney" has been recently proposed to describe a somewhat heterogenous group of renal masses grossly composed of cystic and solid areas and histologically characterized by a mixture of stromal and epithelial cell proliferation. ${ }^{1,2}$ It is a rare, typically benign tumour of the kidney that almost exclusively occurs in perimenopausal women. ${ }^{3,4}$

This entity of tumours with similar morphologic findings

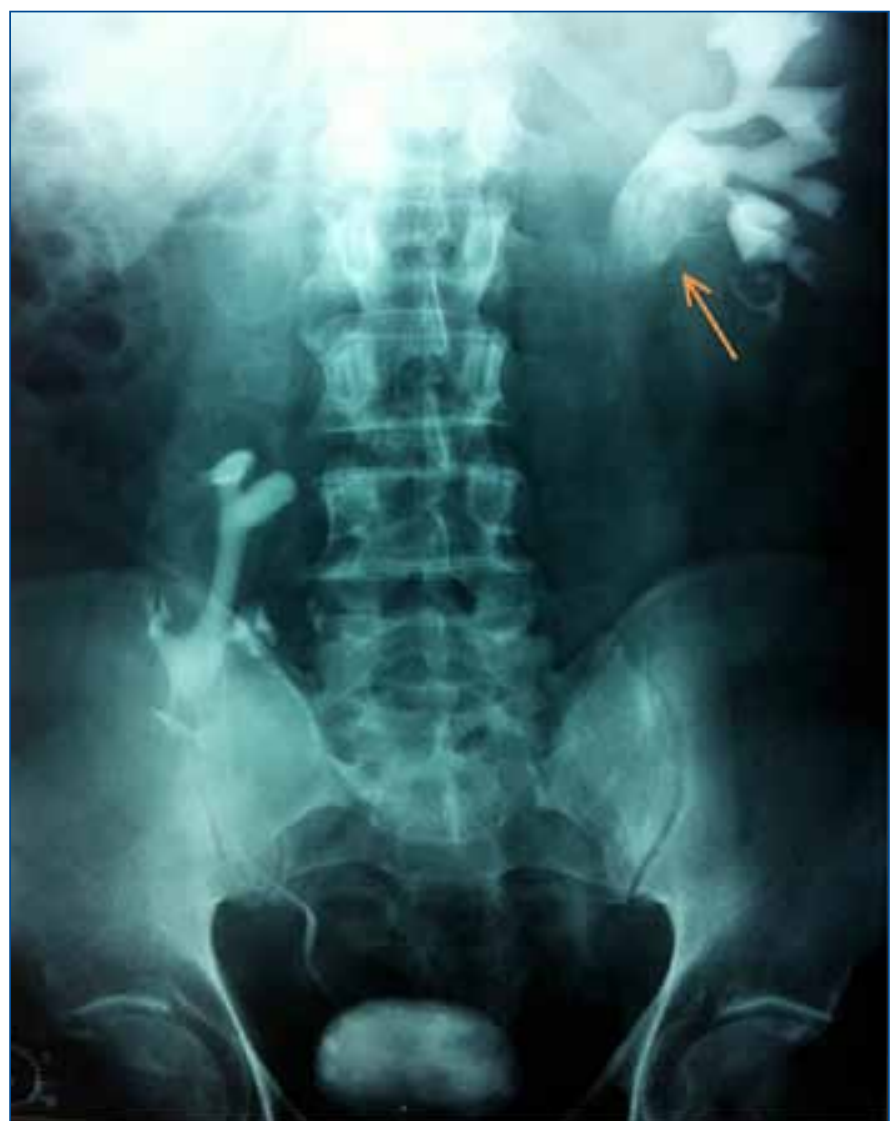

Fig. 2. Excretory urogram. An irregular filling defect is noted in the renal pelvis extending into the middle and lower major calyces and the lower mirror calyces of the left kidney (arrow). There is a mild dilatation of the renal collecting system. The right kidney is ectopic, rotaded and located in the small pelvis.

had been previously described under various diagnoses, such as adult type mesoblastic nephroma, ${ }^{5-8}$ cystic hamartoma of the renal pelvis, ${ }^{9,10}$ cystic nephroma ${ }^{11}$ or mature nephroblastic nephroma and cystic partially differentiated nephroblastoma. ${ }^{12,13}$

Of the 100 reported cases of MEST in the literature, there are only 8 cases of men, including our case. ${ }^{14-16}$ There is a possible hormonal pathogenetic mechanism involved in MEST - most female perimenopausal patients take longterm estrogen replacement therapy and the men with MEST have a history of hormone therapy. ${ }^{2,3}$ However, in our

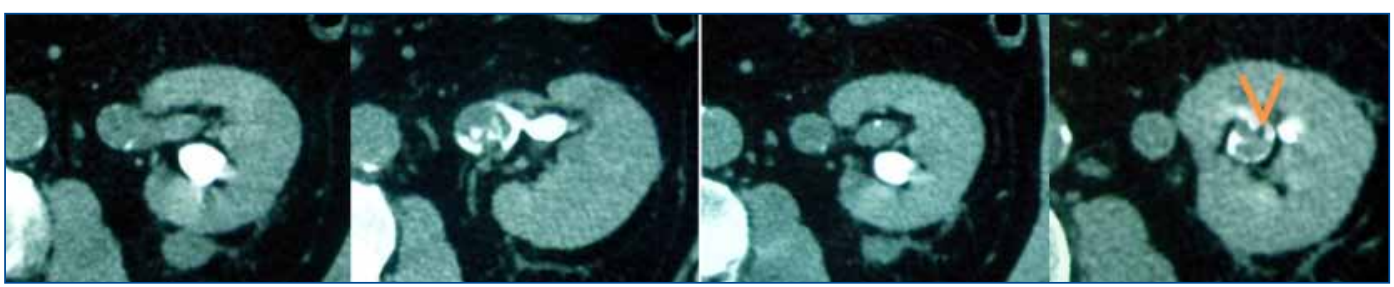

Fig. 3. Axial computed tomography scan at the level of the renal pelvis and lower pole of the left kidney. An irregular filling defect is noted in the renal pelvis and in the lower group of calyces. (arrowhead). 


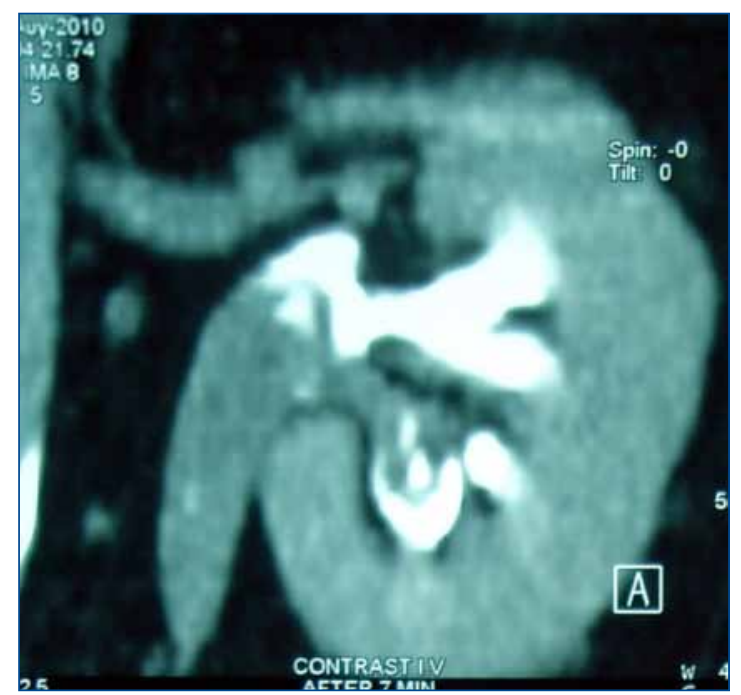

Fig. 4. A computed tomography urography 7 minutes after the administration of intravenous contrast medium. An irregular filling defect is noted in the renal pelvis, extending into the lower group of calyces and upper ureter.

case, as in the case by Kwon and colleagues, there was no evidence of a hormonal receptor expression. Therefore, not all MEST cases implicate a hormonal mechanism. ${ }^{17}$

Common clinical presentations of MESTs are those of renal masses, such as flank pain, hematuria or infection, although about $25 \%$ of MESTs are asymptomatic and incidentally identified, as in our case. ${ }^{2,3}$

With regard to the radiologic features of MEST, the typical computed tomography appearance is that of a wellcircumscribed multiloculated complex renal mass with a variable proportion of solid and cystic components with heterogeneous and delayed contrast material enhancement. ${ }^{18-21}$

The case presented does not share those classic radiologic features. There is indeed evidence that MEST can mimic a variety of cystic renal lesions, including adult cystic nephroma, cystic renal cell carcinoma, complex cyst, multicystic dysplastic kidney or even solid masses, such as renal angiomyolipomas in cross-sectional imaging studies. ${ }^{2,20}$ This is also the reason why MEST is so problematic to diagnose based on preoperative imaging studies alone; up to $70 \%$ of these tumours are classified as Bosniak type III or IV. ${ }^{3}$

In our case, the tumour in imaging studies (IVU, CTU) was demonstrated as an irregular filling defect involving the renal pelvis and the lower group of calyces and extending into the upper ureter. This is likely the second reported case of MEST "herniating" into the renal pelvis and simulating a TCC and the first one with positive urine cytology. ${ }^{22}$

Another fact that differentiates our case from most MEST cases is the presence of positive urine cytology. This finding raises questions regarding the malignant potential of MESTs, although the short-term follow-up of our case is

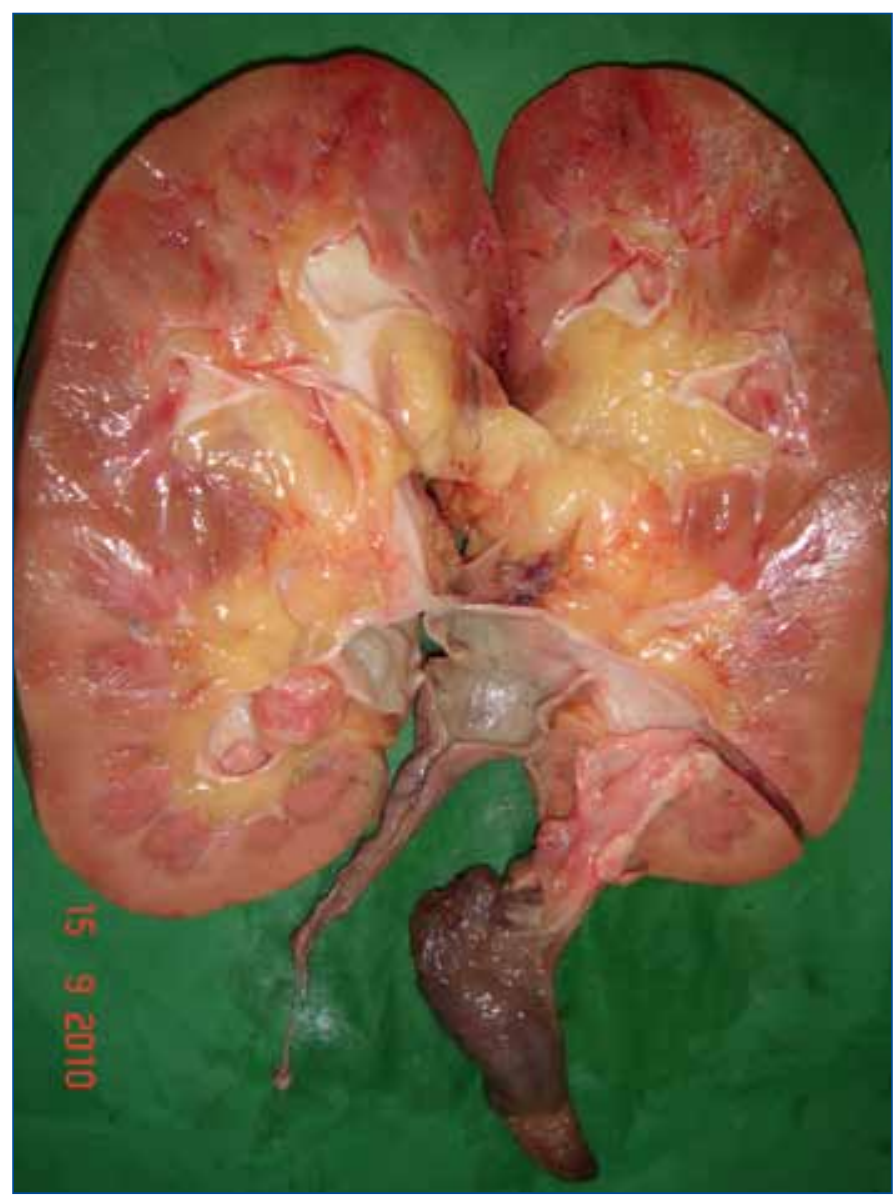

Fig. 5. Bivalved surgical specimen of the kidney and upper ureter.

currently negative for local recurrence or any other signs of malignancy.

In most cases, MESTs behave in a benign fashion following surgery. There have been a few reported cases of local recurrence following surgical resection of malignant sarcoma associated with MEST. ${ }^{23,24}$ Given the rarity of MEST, it is difficult to determine whether these reports of malignant sarcoma represent true malignant transformation from underlying MEST.

According to authors of small case series of MEST, the diagnosis of MEST should be considered in (a) middle-aged women; (b) women with a history of exposure to exogenous estrogen; (c) patients cystic renal tumours with delayed contrast enhancement; and (d) patients with tumours arising from the renal pelvis with negative urine cytologic findings. ${ }^{14,20}$

Our case shares none of these characteristics. Given that MEST is a relatively novel category of renal neoplasms, it is reasonable to believe that the pathological characteristics, radiological features clinical behaviour and appropriate follow-up strategy of this entity of tumours are neither uniform nor yet completely defined. 


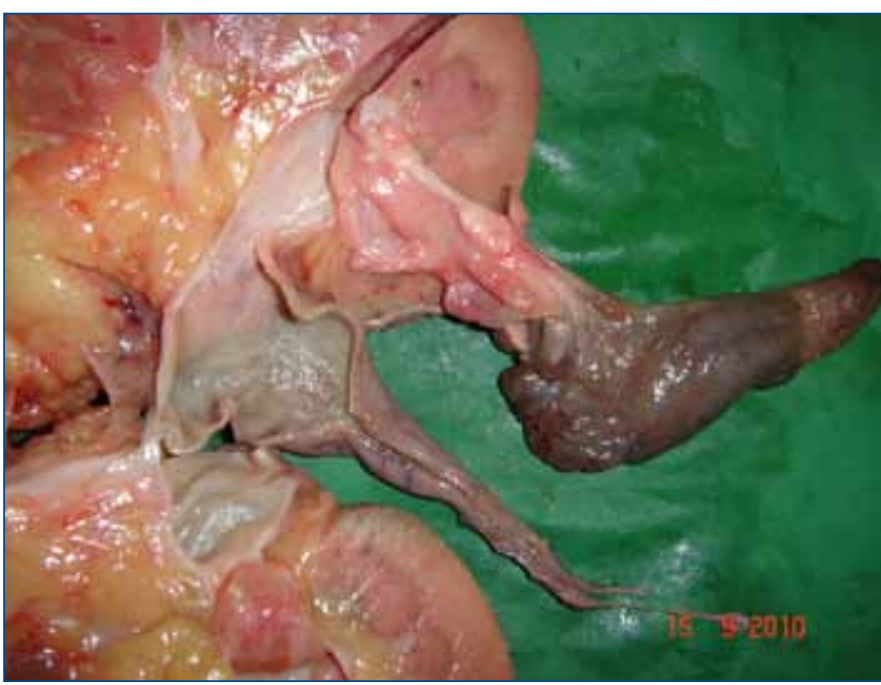

Fig. 6. The brownish tumor is deriving from a lower pole calyx and filling the renal pelvis and upper ureter.

\section{Conclusion}

Our case highlights the dilemmas in the diagnosis and management of controversial cases. One could argue that biopsy of the lesion by means of ureteroscopy would be diagnostic. Still, given the unpredictable natural history of MESTs, it would be somewhat risky not to proceed with nephroureterectomy. On the other hand, given that repeat urine cytologies were negative postoperatively, one would consider a less strict cystoscopic follow-up strategy.

Competing interests: None declared.

This paper has been peer-reviewed.

\section{References}

1. Michal M, Syrucek M. Benign mixed epithelial and stromal tumor of the kidney. Pathol Res Pract 1998;194:445-8. http://dx.doi.org/10.1016/S0344-0338(98)80038-1

2. Adsay NV, Eble JN, Srigley JR, et al. Mixed epithelial and stromal tumor of the kidney. Am I Surg Pathol 2000;24:958-70. http://dx.doi.org/10.1097/00000478-200007000-00007

3. Lane BR, Campbell SC, Remer EM, et al. Adult cystic nephroma and mixed epithelial and stromal tumor of the kidney: clinical, radiographic, and pathologic characteristics. Urology 2008;71:1142-8. http:// dx.doi.org/10.1016/i.urology.2007.11.106
4. Moslemi MK. Mixed epithelial and stromal tumor of the kidney or adult mesoblastic nephroma: an update. J Urol 2010;7:141-7.

5. Durham JR, Bostwick DG, Farrow GM, et al. Mesoblastic nephroma of adulthood. Report of three cases. Am J Surg Pathol 1993; 17:1029-38. http://dx.doi.org/10.1097/00000478-199310000-00008

6. Truong LD, Williams R, Ngo T, et al. Adult mesoblastic nephroma: expansion of the morphologic spectrum and review of literature. Am J Surg Pathol 1998;22:827-39. http://dx.doi.org/10.1097/00000478199807000-00005

7. Trillo AA. Adult variant of congenital mesoblastic nephroma. Arch Pathol Lab Med 1990;114:533-5.

8. Daniel L, Lechevallier E, Bouvier C, et al. Adult mesoblastic nephroma. Pathol Res Pract 2000;196:135-9. http://dx.doi.org/10.1016/S0344-0338(00)80046-1

9. Pawade J, Soosay GN, Delprado W, et al. Cystic hamartoma of the renal pelvis. Am I Surg Pathol 1993;17:1169-75. http://dx.doi.org/10.1097/00000478-199311000-00010

10. Yoshida S, Nakagomi K, Goto S, et al. Cystic hamartoma of the renal pelvis. Int J Urol 2004;11:653-5. http://dx.doi.org/10.1111/j.1442-2042.2004.00866.x

11. Aoyagi T, Kakudo K, Satoh $S$, et al. Multilocular cystic nephroma in an adult: immunohistochemical study. J Urol 1987;138:397-9.

12. Nagao T, Sugano I, Ishida Y, et al. Cystic partially differentiated nephroblastoma in an adult: an immunohistochemical, lectin histochemical and ultrastructural study. Histopathology 1999;35:65-73. http:// dx.doi.org/10.1046/i.1365-2559.1999.00687.x

13. Freeby JA, Fishman EK, Marshall FF, et al. Mesoblastic nephroma in an adult: spiral CT appearance. Abdom Imaging 1997;22:439-40. http://dx.doi.org/10.1007/s002619900228

14. Mohd Zam NA, Lau WK, Yip SK, et al. Mixed epithelial and stromal tumour (MEST) of the kidney: a clinicopathological report of three cases. Pathology 2009;41:403-6. http://dx.doi. org/10.1080/00313020902886944

15. Mai KT, Elkeilani A, Veinot JP. Mixed epithelial and stromal tumour (MEST) of the kidney: report of 14 cases with male and PEComatous variants and proposed histopathogenesis. Pathology 2007;39:235-40. http://dx.doi.org/10.1080/00313020701230799

16. Jevremovic D, Lager DJ, Lewin M. Cystic nephroma (multilocular cyst) and mixed epithelial and stromal tumor of the kidney: a spectrum of the same entity? Ann Diagn Pathol 2006;10:77-82. http://dx.doi. org/10.1016/i.anndiagpath.2005.07.011

17. Kwon JE, Kang JH, Kwon GY. Mixed epithelial and stromal tumor of the kidney: a case report. J Korean Med Sci 2007;22:159-62. http://dx.doi.org/10.3346/kkms.2007.22.1.159

18. Park HS, Kim SH, Kim SH, et al. Benign mixed epithelial and stromal tumor of the kidney: imaging findings. J Comput Assist Tomogr 2005;29:786-9. http://dx.doi.org/10.1097/01.rct.0000176016.75169.c9

19. Sahni VA, Mortele KJ, Glickman J, et al. Mixed epithelial and stromal tumour of the kidney: imaging features. BJU Int 2010;105:932-9. http://dx.doi.org/10.1111/i.1464-410X.2009.08918.x

20. Chu LC, Hruban RH, Horton KM, et al. Mixed epithelial and stromal tumor of the kidney: radiologicpathologic correlation. Radiographics 2010;30:1541-51. http://dx.doi.org/10.1148/rg.306105503

21. Lang N, Li J, Liu JY, et al. Mixed epithelial and stromal tumor of the kidney: an analysis of multidetector computed tomography manifestations and clinicopathologic findings. J Comput Assist Tomogr 2010;34:177-81. http://dx.doi.org/10.1097/RCT.0b013e3181c78fa3

22. Johnson PT, Horton KM, Fishman EK. Optimizing detectability of renal pathology with MDCT: protoาcols, pearls and piffalls. AJR Am J Roentgenol 2010;194:1001-2. http://dx.doi.org/10.2214/AJR.09.3049

23. Nakagawa $\mathrm{T}$, Kanai Y, Fujimoto $\mathrm{H}$, et al. Malignant mixed epithelial and stromal tumours of the kidney: a report of the first two cases with a fatal clinical outcome. Histopathology 2004;44:302-4. http:// dx.doi.org/10.1111/i.1365-2559.2004.01782.x

24. Yap YS, Coleman M, Olver I. Aggressive mixed epithelial-stromal tumour of the kidney treated with chemotherapy and radiotherapy. Lancet Oncol 2004;5:747-9. http://dx.doi.org/10.1016/S14702045(04)01651-1

Correspondence: Dr. Petros Sountoulides, Agiou Evgeniou 15-17, 55133, Thessaloniki, Greece; sountp@hotmail.com 